\title{
A protracted experiment
}

Some measurements of the dark-energy reflux density...

Bates Lenniteri's fingers and bow danced on his violin as black holes exploded around him.

They had just begun Brahms's first symphony. The wind howled at the North Pole. Bates's dome tent shuddered.

But his fingers didn't dance as well as the Vienna Philharmonic's conductor wished - she tut-tutted her baton at Bates for playing too softly; and the minuscule black holes didn't so much explode, as the ads said, as evaporate rapidly and softly into the ripples of the tent's HeaTec fabric.

In his spex Bates saw the conductor scowl at him, her eye-flash reminding him that this was a live performance, not practice. He saw the other musicians arrayed around him virtually, translucent ghosts beaten by the snapping tent. Software added their tuxes. Bates eyed the concertmaster for glimmers that he might be advertising on the Market for a replacement to take over his role. Satisfied hed earn this joblet's bread tonight, he peeked at his dark-energy experiment, open in another spex window.

It drained his account to pay fractions of pennies for each infinitesimal measurement of the dark-energy reflux density around countless black holes evaporating in everyday consumer products worldwide. It was, ultimately, to scrape together enough cash from joblets - to pay for wedding and baby - that he was crewing a polarmax sled-tanker. Now broken down. Stranding him for weeks. Keeping them apart. He knew she understood, his loving Aimee Cuirr. His red-haired beauty smiled at him from among the cellos, where her ratings earned her a chair. Her GPS coordinates placed her at her mum's home in Dublin.

But he couldn't sacrifice the experiment - proving his thesis that minor variations in the dark-energy reflux density near black holes caused the predominance of matter over antimatter in the Universe. Now that would set him up for life. Possibly even a tenured position, he dreamed, although ten-yeared was more realistic. It had certainly launched his adviser's career, the esteemed Knight Aspenhew, to discover that the mysterious DERD was indisputably an interaction with the... something... that lay outside our Universe.

Bates's research breakthrough had been connecting with the anti-Smolinites. Perennially broke sorts of people on the edge of spexlessness, and irrationally afraid of black holes no matter how safe they were proven, they latched onto his nanopennies.
They relished measuring something, anything, that might discredit Smolin's now widely believed conjecture that our Universe was quasidarwinianly evolved and optimized for blackhole creation. Helping Bates translated (in their warped minds) to doing something, anything, to stop the infinitudes of evil black holes decanted from the void to power toys and metropoli.

Thank God for

Aimee's research. Not only was it how they met, it enabled Bates to test his thesis. Difficult to measure directly, DERD was easily measured indirectly, and very precisely, through Aimee's brilliant off-the-shelf innovation. Her dissertation had shown the way, by measuring over the incredible numbers of black holes that were unvoided and evaporated in common products such as HeaTec. As the Brahms performance continued, his worldwide masses of data were poised to deliver the margin of error he needed to satisfy his adviser.

Measurements flooded in with the horns. Bates bowed like the devil and watched his credit balance deflate. At every wavelength, his test data graphically filled the curve he predicted they should take beautifully. He could taste his PhD. His final article was already written and pre-approved by his adviser, awaiting only statistically significant confirmation from this experiment. A blink away from submission to Nature Physics and the feral ratings-review game. The title was sufficiently pompous and subtle: 'Some measurements of the dark energy reflux density and implications for universe evolution'; or as Bates joked, 'Why choosy quarks choose matter'.

Late in the second movement. Almost enough data points for his margin of error target. Almost... almost... any moment... All the views of the data looked perfect. Until - he blinked up a three-dimensional time-variant view. It should be constant yet - it was a mess. He groaned aloud.

The conductor glared at him.

It wouldn't converge within acceptable error. The damn thing wasn't constant; it had a shape! There would be questions.
Doubts. Untold years more toil or, worse, a dead end. He felt his degree, his career, his future, evaporating. With a sigh as the third movement began he submitted the strange curve to the Market, hoping for a free analysis from the open-source networks. Maybe there was an obvious meaning. The curve looked familiar somehow. Mesmerizing.

As the third movement progressed, Bates relaxed some. Every simple theory seemed to have its hitch. Newton's found by Einstein, and even Einstein cursed his own cosmological constant. To hell with Occam and the original 'keep it simple, stupid' theory. The corollary was: nothing's ever as simple as it seems. He paced the tent, bowing, fingering, figuring.

As the fourth movement built to a climax Bates blinked through his curve analysis replies. Spam for high-priced analysis firms. Bunch of clowns with guesses, begging a few pennies. And this! A freebie, no less, from a friendly marine biologist in Sydney. "Hey, mate, I recognize that curve exactly," his message said.

Bates dropped his bow. Wind howled.

"It's part of the acoustic pattern I recorded near the great barrier reef of a barracuda chasing a puffer fish. Say, what's it got to do with cosmology?"

The Brahms crescendoed to an end. Black holes exploded around him.

\section{Andrew Burt}

Andrew Burt's various hats include writer, computer-science professor, chief executive, consultant, philosopher and, for a hobby, solver of the world's problems (fortunately nobody listens); his website is www.aburt.com. 